\title{
KARAKTERISTIK OPTIK DAN KRISTAL NANOPARTIKEL MAGNETIT
}

\author{
T. SARAGI *, B PERMANA, M SAPUTRI, L SAFRIANI, I RAHAYU, RISDIANA \\ Departemen Fisika, FMIPA, Universitas Padjadjaran \\ Jl. Raya Bandung-Sumedang Km.21 Jatinangor 45363, Sumedang, Jawa Barat \\ *email :t.saragi@phys.unpad.ac.id
}

\begin{abstract}
Abstrak. Oksida besi, nanopartikel magnetit $\left(\mathrm{Fe}_{3} \mathrm{O}_{4}\right)$, memiliki sifat yang berbeda dan lebih menarik daripada material bulk-nya. Selain itu, material ini dapat diaplikasikan secara lebih luas dan efektif pada ukuran nanometernya seperti ferrofluids, media penyimpanan data, pigmen warna, dan katalis. Pada penelitian ini telah berhasil dikarakterisasi sifat optik dan struktur kristal dari nanopartikel magnetit dengan menggunakan teknik Spektroskopi UV-Vis dan teknik difraksi sinar-X. Karakterisasi material nanopartikel magnetit berdasarkan variasi suhu sintering, $80^{\circ} \mathrm{C}$ dan $1100^{\circ} \mathrm{C}$. Berdasarkan hasil karakterisasi UV-Vis diperoleh bahwa energi-gap dari nanopartikel $\mathrm{Fe}_{3} \mathrm{O}_{4}$ ini berada pada rentang energi-gap semikonduktor, $0-3 \mathrm{eV}$. Berdasarkan hasil karakterisasi XRD diperoleh bahwa Variasi suhu sintering menyebabkan berubahan struktur kristal oksida besi yang diperoleh, yaitu magnetit $\left(\mathrm{Fe}_{3} \mathrm{O}_{4}\right)$ dengan struktur kubik pada suhu $80^{\circ} \mathrm{C}$, dan hematit $\left(\alpha-\mathrm{Fe}_{2} \mathrm{O}_{3}\right)$ dengan struktur hexagonal pada suhu $1100^{\circ} \mathrm{C}$, sesuai dengan data JCPDS.
\end{abstract}

Kata kunci : $\mathrm{Fe}_{3} \mathrm{O}_{4}, \alpha-\mathrm{Fe}_{2} \mathrm{O}_{3}$, Sintering, UV-Vis, $\mathrm{XRD}$

\begin{abstract}
Iron Oxide, magnetit $\left(\mathrm{Fe}_{3} \mathrm{O}_{4}\right)$ nanoparticles, has different and more interesting properties than it's bulk materials. Besides that, in nanometer scale, this material can apply more effective and wide application like ferrofluids, data storage, color pigment, and catalyst. In this papper, we have been successfully characterized the optical and crystal structur from magnetit nanoparticles by using UV-Vis spectroscopy and X-ray diffraction technique depends on variation of sintering temperature of $80^{\circ} \mathrm{C}$ and $1100^{\circ} \mathrm{C}$. From UV-Vis characterization, it was found that the band-gap of sample was around of semiconductor band-gap, $0-3 \mathrm{eV}$. From XRD characterization, it was found that the variation of sintering temperature can changed the crystal structure of iron oxide, magnetite $\left(\mathrm{Fe}_{3} \mathrm{O}_{4}\right)$ with cubic structure on $80^{\circ} \mathrm{C}$, hematite $\left(\alpha-\mathrm{Fe}_{2} \mathrm{O}_{3}\right)$ with hexagonal strucrute on $1100^{\circ} \mathrm{C}$, compared with JCPDS data.
\end{abstract}

Keywords : $\mathrm{Fe}_{3} \mathrm{O}_{4}, \alpha-\mathrm{Fe}_{2} \mathrm{O}_{3}$, Sintering, UV-Vis,XRD

\section{Pendahuluan}

Nanopartikel magnetit $\left(\mathrm{Fe}_{3} \mathrm{O}_{4}\right)$ merupakan material yang menarik dan memiliki aplikasi yang sangat luas. Dalam grup spinel, bahan magnetit $\left(\mathrm{Fe}_{3} \mathrm{O}_{4}\right)$ adalah salah satu jenis dari fasa mineral oksida besi, selain maghemit $\left(\gamma-\mathrm{Fe}_{2} \mathrm{O}_{3}\right)$ dan hematit $(\alpha-$ $\mathrm{Fe}_{2} \mathrm{O}_{3}$ ). Magnetit memiliki struktur kimia $\mathrm{FeO}-\mathrm{Fe}_{2} \mathrm{O}_{3}$ dimana satu bagian adalah wustite $(\mathrm{FeO})$ dan bagian lainnya adalah hematit $\left(\mathrm{Fe}_{2} \mathrm{O}_{3}\right)$. Material ini memiliki struktur kristal kubik-spinel yang tersusun dari ion-ion oksigen, $\mathrm{Fe}^{2+}$, dan ion-ion $\mathrm{Fe}^{3+}$ dan termasuk ke dalam bahan ferrimagnetik [1].

Sifat optik dari nanopartikel magnetit $\left(\mathrm{Fe}_{3} \mathrm{O}_{4}\right)$ bergantung pada ukuran dari partikel magnetit tersebut, dan energi-gap berkisar pada energi-gap semikonduktor yaitu 0- 
$3 \mathrm{eV}[2,3]$. Struktur kristal dari magnetit dapat berubah melalui tahapan sintering. Pada suhu dibawah $100^{\circ} \mathrm{C}$, magnetit memiliki struktur kristal kubik spinel. Pada suhu diatas $100^{\circ} \mathrm{C}$ hingga $600^{\circ} \mathrm{C}$, magnetit mengalami perubahan fasa menjadi maghemit dengan struktur kristal kubik dan tetragonal. Pada suhu $1000^{\circ} \mathrm{C}-1100^{\circ} \mathrm{C}$ terjadi perubahan fasa dan kembali menjadi hematit dengan struktur kristal rhombohedral seperti yang dilakukan oleh Kazeminezhad [4]. Pada penelitian sebelumnya, kami telah berhasil mengamati struktur kristal hexagonal pada oksida besi yang disintesis melalui metode hidrotermal dengan suhu sintering $1100^{\circ} \mathrm{C}$ [5]. Pada paper ini, kami kembali melakukan pengamatan struktur kristal oksida besi pada suhu sintering $1100^{\circ} \mathrm{C}$ melalui metode sintesis yang berbeda untuk menguatkan bukti pengamatan kami pada penelitian sebelumnya. Pada paper ini juga diamati struktur kristal oksida besi pada suhu sintering $80^{\circ} \mathrm{C}$.

\section{Metode Penelitian}

Sintesis oksida besi magnetit $\left(\mathrm{Fe}_{3} \mathrm{O}_{4}\right)$ dilakukan melalui proses kopresipitasi pada suhu sintesis $25^{\circ} \mathrm{C}$ dan $\mathrm{pH}=10$. Prekursor yang digunakan adalah $\mathrm{FeCl}_{3} \cdot 6 \mathrm{H}_{2} \mathrm{O}$ dan $\mathrm{FeCl}_{2} \cdot 4 \mathrm{H}_{2} \mathrm{O}$. Kedua prrekursor dengan perbandingan molar tertentu dilarutkan kedalam DI-Water dan diaduk selama 60 menit pada suhu ruang. Setelah larutan homogen, $\mathrm{NH}_{4} \mathrm{OH}$ ditambahkan tetes demi tetes hingga mencapai $\mathrm{pH}=10$. Selanjutnya dilakukan proses pencucian dengan menggunakan $n$-hexane dan etanol sebanyak dua kali dan didispersikan ulang pada larutan etanol. Karakterisasi optik dan struktur kristal masing-masing dilakukan dengan pengukuran UV-Vis dan XRD. Energi-gap dari sampel dihitung berdasarkan data UV-Vis dengan menggunakan persamaan $\mathrm{Eg}=\mathrm{hc} / \lambda_{\text {cut-off. }}$ Untuk mengamati struktur kristal, kemudian sampel di keringkan dan disintering pada suhu $80^{\circ} \mathrm{C} 1100^{\circ} \mathrm{C}$.

\section{Hasil dan Pembahasan}

Spektrum absorbansi nanopartikel $\mathrm{Fe}_{3} \mathrm{O}_{4}$ melalui pengukuran UV-Vis ditunjukkan pada Gambar 1. Berdasarkan Gambar 1, diperoleh bahwa panjang gelombang cutoff adalah $559 \mathrm{~nm}$, yang setara dengan energi-gap sebesar 2,22 eV. Nilai ini masih berada pada rentang semikonduktor, $0-3 \mathrm{eV}$, sesuai dengan beberapa penelitian yang telah dilakukan sebelumnya $[3,6]$.

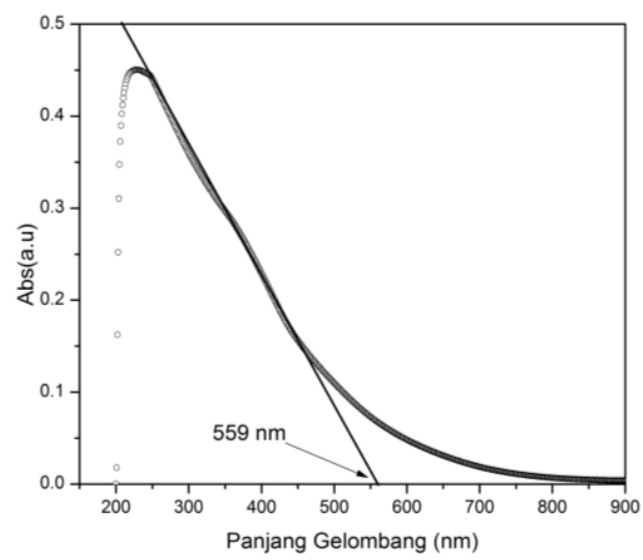

Gambar 1. Spektrum UV-Vis sampel magnetit $\left(\mathrm{Fe}_{3} \mathrm{O}_{4}\right)$ yang disintesis dengan metode kopresipitasi pada suhu $25^{\circ} \mathrm{C}$ dan $\mathrm{pH}=10$ 
Hasil pengukuran XRD sampel oksida besi setelah sintering pada suhu $80^{\circ} \mathrm{C}$ dan $1100^{\circ} \mathrm{C}$ ditunjukkan pada Gambar 2 dengan data pembanding JCPDS\#1309-37-1 untuk fasa $\mathrm{Fe}_{3} \mathrm{O}_{4}$ kubik dan JCPDS\#11-614 untuk fasa $\alpha-\mathrm{Fe}_{2} \mathrm{O}_{3}$ hexagonal. Berdasarkan Gambar 2 tersebut diperoleh bahwa sampel yang disintering pada suhu $80^{\circ} \mathrm{C}$ memiliki struktur kristal kubik, dan sampel yang disintering pada suhu $1100^{\circ} \mathrm{C}$ memiliki struktur kristal hexagonal. Struktur kristal yang diperoleh pada penelitian ini sama dengan struktur kristal yang diperoleh pada penelitian sebelumnya, oksida besi yang disintesis melalui metode hidrotermal dengan suhu sintering $1100^{\circ} \mathrm{C}$ yaitu hexagonal [5] dan berbeda dengan struktur sebagaimana dilaporkan oleh Kazeminezhad [4]. Perubahan fasa oksida besi dari $\mathrm{Fe}_{3} \mathrm{O}_{4}$ dengan struktur kristal kubik menjadi $\alpha-\mathrm{Fe}_{2} \mathrm{O}_{3}$ dengan struktur kristal hexagonal dapat terjadi karena perubahan posisi ion-ion penyusunnya ketika proses sintering. Puncak-puncak yang diperoleh pada sampel ini sesuai dengan puncak-puncak pada data JCPDS.

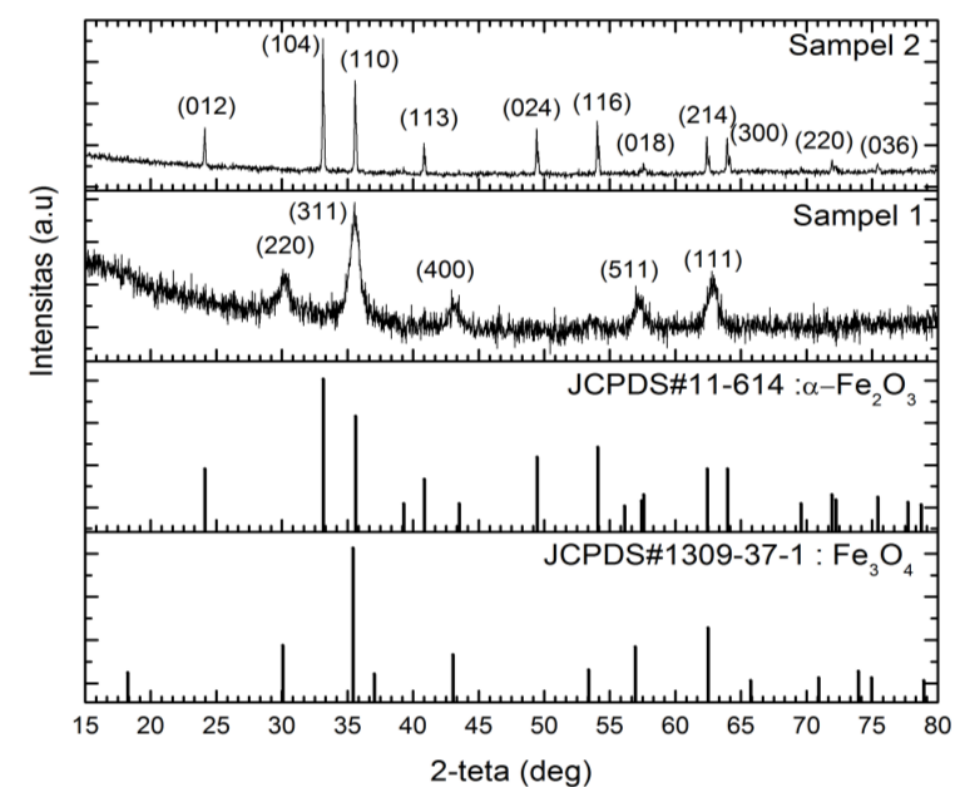

Gambar 2. Pola XRD : (a) serbuk oksida besi pada penelitian sebelumnya, (b) serbuk oksida pada penelitian saat ini untuk suhu sintering $80^{\circ} \mathrm{C}$ (sampel 1) dan suhu sintering $1100^{\circ} \mathrm{C}$

\section{Kesimpulan}

Sintesis nanopartikel oksida besi $\mathrm{Fe}_{3} \mathrm{O}_{4}$ dengan metode kopresipitasi telah berhasil dilakukan. Energi gap nanopartikel adalah sebesar 2,22 eV dan berada pada rentang energi-gap semikonduktor. Dari hasil pengukuran XRD, diperoleh bahwa sampel yang disintering pada suhu $80^{\circ} \mathrm{C}$ masih memiliki fase magnetit $\mathrm{Fe}_{3} \mathrm{O}_{4}$ dengan ukuran kristalit rata-rata berkisar sampel $27,17 \mathrm{~nm}$, sedangkan sampel yang disintering pada suhu $1100^{\circ} \mathrm{C}$ mengalami perubahan fase dari magnetit menjadi hematit $\alpha-\mathrm{Fe}_{2} \mathrm{O}_{3}$ dengan ukuran kristalit rata-rata berkisar $81,02 \mathrm{~nm}$. Struktur kristal yang diperoleh pada suhu sintering $1100^{\circ} \mathrm{C}$ pada penelitian ini memiliki struktur kristal yang sama dengan struktur kristal pada penelitian sebelumnya yang juga disintering pada suhu $1100^{\circ} \mathrm{C}$. 


\section{Ucapan terima kasih}

Penelitian ini didanai oleh Hibah Internal Universitas Padjadjaran 2017, melalui Program Riset Fundamental Unversitas Padjadjaran (RFU) 2017, No. 855/UN6.3.1/PL/2017, dan sebahagian melalui Program Academic Leadership Grant of Universitas Padjadjaran 2017, No. 872/UN6.3.1/LT/2017.

\section{Daftar Pustaka}

1. S. Bijaksana M. P. Aji dan A. Yulianto, Sintesis nano partikel magnetit, maghemit dan hematit dari bahan lokal," J. of Materials Sci., (2007) 106-108.

2. L. Pranita dan J. Preeti, Research in Chemistry and Environment Preparation and Characterization of Magnetite Nanoparticle using Green Synthesis, 5 (2015) 4.

3. H. E. Ghandoor, H, Zidan, M. M. Khalil, dan M. I. Ismail, "Synthesis and Some Physical Properties of Magnetite (Fe3O4) Nanoparticles," Int. J. Electrochem, 7 (2012) 5734-5745.

4. I. Kazeminezhad dan S. Mosivand, "Phase Transition of Electrooxidized Magnetite to maghemite and hematite Nanoparticles Using Sintering Treatment," Acta Phys. Pol. A, 125 (2014) 5, 1210-1214.

5. T. Saragi, A.S. Santika, B. Permana, N. Syakir, M. Kartawidjaja, and Risdiana, IOP Conf. Series: Materials Science and Engineering (2017), 196012025.

6. P. Mallick dan B. N. Dash, X-ray Diffraction and UV-Visible Characterizations of $\alpha-\mathrm{Fe} 2 \mathrm{O} 3$ Nanoparticles Annealed at Different Temperature, 3 (2013) 5, 130134.

7. T. Ida, A. Ceramics, U. Jan, dan S. Just, "Diffraction from small crystallites," in Crystal Structure Analysis, Nagoya: Nagoya Institute of Technology, 2015.

8. Trif L, Tolnai G, Sajo I and Kalman E, Progr. Colloid Polym. Sci. 135 (2008) 38

9. F. Girgsdies, "Peak Profile Analysis in X-ray Powder Diffraction," Fritz-HaberInstitut der MPG, Berlin. 